\title{
Numerical study on steel-concrete composite floor systems under corner column removal scenario
}

\author{
Qiu Ni Fu ${ }^{a *}$ and Kang Hai Tan ${ }^{a}$ \\ ${ }^{a}$ School of Civil \& Environmental Engineering, Nanyang Technological University, 50 Nanyang Avenue, \\ Singapore \\ *corresponding author, e-mail address: fuqi0002@e.ntu.edu.sg
}

\begin{abstract}
This paper evaluates the robustness of steel-concrete composite floor systems subjected to Corner Column (CC) removal scenario based on numerical simulations. Firstly, a FE model is statically analysed subjected to a $\mathrm{CC}$ removal scenario, yielding the static loaddisplacement curve, the failure mode and load-transfer mechanisms. These results are compared with those of composite floor systems under an Internal Column (IC) removal scenario. Besides, the FE model was dynamically analysed by six times under the respective six levels of loads by suddenly removing the corner column. The dynamic displacement-time responses under all levels of loads were obtained. Six pairs of load versus peak displacement constitute the pseudo-static response, to assess the loadcarrying capacity and ductility of this composite floor system subjected to a sudden corner-column-removal scenario. Lastly, dynamic increase factors (DIFs) are obtained through comparing the quasi-static and pseudo-static responses, which is further compared with DIF under IC scenario.
\end{abstract}

Keywords: Progressive collapse; Composite structures; Column-removal scenario; Dynamic behaviour; Numerical study

\section{Introduction}

The "911" event arouses world-wide researchers' interests in studying progressive collapse. Consequently, a lot of numerical simulations come out, aiminig to study the collapse behaviour of entire buildings under extreme loads. However, beam-to-column and beam-to-beam connections were usaully simplified as pins, where were not sufficiently accurate to capture the behaviour of joints subjected to large deforamtion. In fact, joint behaviour can significantly influence the overall performance of a building, so researchers should adopt more refined joint models. Until the last decade, a number of experimental studies started to shed light on structural behaviour of sub-strucutres, such as joint components, 2D beam-column assemblies and 3D beam-slab floor systems, based on column remvoal scenarios. Certainly, tesing 3D floor systems can yield the most realistic behaviour.
Qian and Li [1] experimentally quantified the slab contribution in RC buildings subjected to loss of a corner column. They [2] also quantified the slab effect on dynamic response of RC structures against progressive collapse. LIM [3] systematically studied the structural behaviour of 2D and 3D RC frames, as well as 3D RC frame-slabs subjected to column removal scenarios.

Chen, Huang [4] launched an experimental programme on a two-storey steel frame composite floor system to investigate the progressive collapse resistance subjected to sudden removal of an edge column. After instantaneously removing the column, the strains of remaining members were far smaller than the yield strains. That is to say, the structural behaviour at large deformation stage was observed or studied. Beisdes, only one free-fall test cannot determine Dynamic Increase Factor (DIF). 
Hull [5] conducted an experimental test on a composite floor system under an Internal Column (IC) loss scenario. Unfortunately, the collapse was caused by artificial action so that they failed to unveil the realistic failure mode of the sub-structure subjected to an internal column loss scenario.

Song and Sezen [6] conducted a field experimental programme on an existing steel building by removing four first-storey columns one after another. The limited experimental results helped researchers to understand some behaviour of full-scale steel frame buildings subjected to column loss scenarios, but were not sufficient to investigate load-resisting mechanisms or failure modes since the structure was not severely damaged.

Johnson, Meissner [7] conducted a halfscale test on a composite floor system under different column removal scenarios. For the $\mathrm{CC}$ removal scenario, the load-carrying capacity was unexpectedly low and equilibrium was not achieved even at the first load level. It means that the load-deflection response was not obtained for the $\mathrm{CC}$ removal scenario.

$\mathrm{Fu}$, Tan [8] experimentallly studied loadresisting mechanisms of $3 \mathrm{D}$ composite floor systems under an internal column-removal scenario. Fu, Tan [9] experimenally revealed the effects of slab aspect ratio, degree of compoiste action and boundary condition on the behaviour of compoiste floor systems subjected to an internal column removal scenario.

From the above literature review, the only test under a CC removal scenario [7] was not carried out successfully. Therefore, there is absence of valid experimental results of steelconcrete composite floor systems subjected to a corner column removal scenario. Besides, although there was a free-fall test on a compoiste floor system [4], the dynamic behaviour at large deforamtion and DIF were not studied. Hence, the authors plans an experimental programme to investigate the static and dynamic behavior of composite floor systems under a corner column removal scenario, and further to study DIF, which are numerically studied in this paper before the commencement of testing.

\section{FE Simulations}

\subsection{Details of floor system}

This section presents the structural configurations of the floor systems modelled in this paper. Fig. 1 shows that the floor system consists of girders (or main beams), beams and inner beams (or secondary beams), and steel decking-concrete compoiste slabs, which is supported by three coloumns with corner column removed. To ensure continuity of the floor system immediately above the removed column, the ajadcent-bay girders, beams and slabs are also included and terminated at the respective approximate inflection points, as shown in Fig. 1 . Previously, the authors [9] have conducted similar floor system tests with the only difference in column removal location. Therefore, the structural confiurations of the floor systems in the two series of studies remain the same. The composite slab is made of profiled steel decking ( $40 \mathrm{~mm}$ deep by 0.9 $\mathrm{mm}$ thick), concrete (65 $\mathrm{mm}$ thick in total), and reinforcement mesh ( $\Phi 6$ at $100 \mathrm{~mm}$ spacing in both directions). The girders are connected to columns with flush-end-plate joint (Fig. 2 (a)), and secondary beams are connected to clumns or girders using double web-cleat joints (Fig. 2 (b)). The details of the slab geometry and the material properties can be found in $\mathrm{Fu}$, Tan [9].

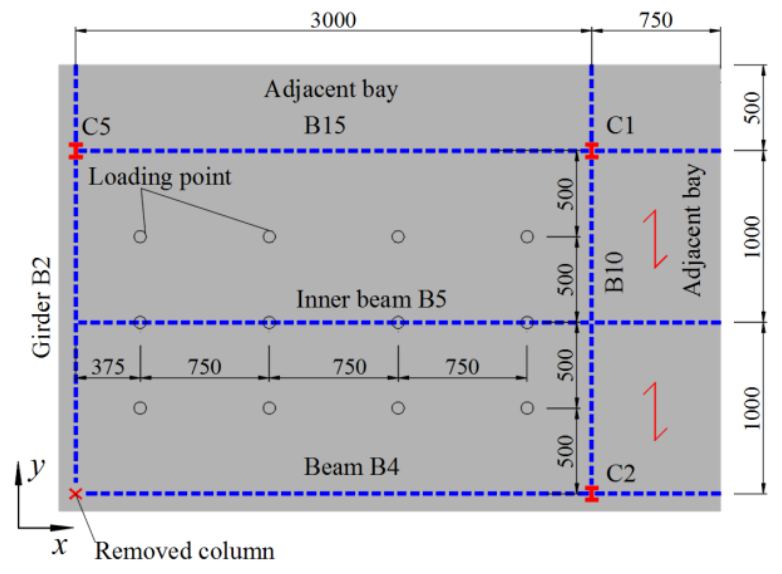

Fig. 1. Structural layout. 


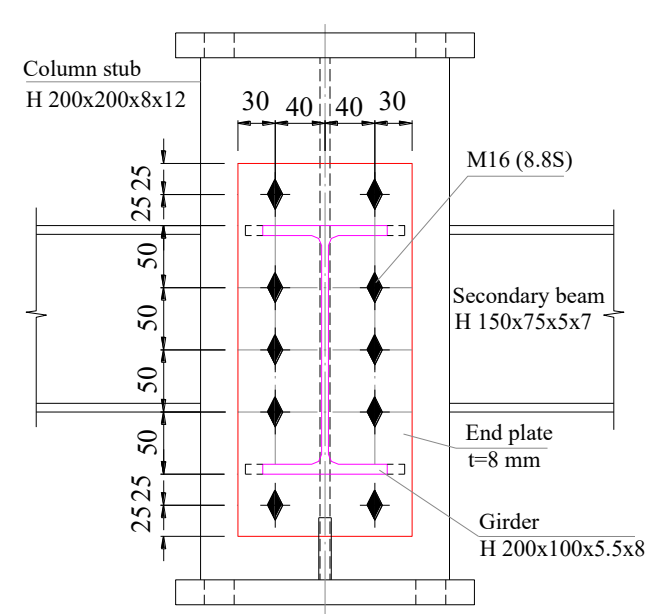

(a) Extended-end-plate for girders

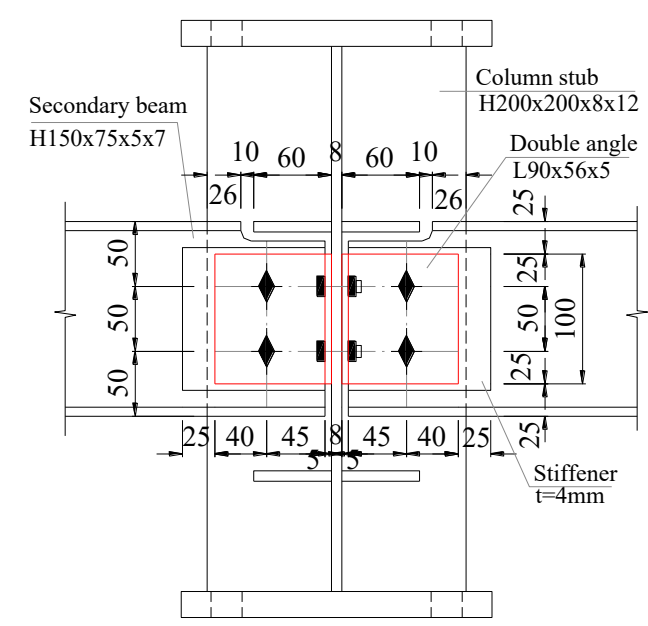

(b) Web-cleat for secondary beams

${ }^{*} \mathrm{H} 200 \times 100 \times 8 \times 12-\mathrm{H}$ represents the "H" shape wide-flange section and the numbers are the depth, flange width, web thickness, and flange thickness in $\mathrm{mm}$, respectively.

\subsection{Descriptions of models}

The modelling method in this paper adopts the one verified by the authors [10], which simulated compoiste floor systems under an IC removal scenario using ABAQUS package. Fig. 3 shows the elements used in the model. The overivews of the models are shown in Fig. 4. The bottom ends of the three columns are fixed, while the cantilever ends of girders and secondary beams in the adjacent bays are vertically and horizontally restrained, as shown in Fig. 4. First, the model is statically applied with the respective UDL (Fig. 4 (a)) and 12-point loads (Fig. 4 (b)) individually. The results under the two loading scenarios are compared in the subsequent section. Second, the model is also dynamically analysed following the sudden remmoval of the corner column.

As shown in Fig. 5, a UDL is quasistatically applied on the slab during Step-1and remains constant during Step-2. On the other hand, in Step-1, the corner column location is also applied with a vertically upward supprting force which is equal to one quarter of the total applied load. At the beginning of Step-2, the supporting force is reduced to zero in $0.08 \mathrm{~s}$ which is one tenth of the period associated with veritical motion of the floor system without the corner column, to simulate sudden loss of the corner column. The proramme continures to run until $2 \mathrm{~s}$, which is long enough to acquire the maximum displacment. In this way, the model is analysed under incresingly greater magnitudes of UDL until the floor system collapses.

Fig. 2. Details of joints [9].

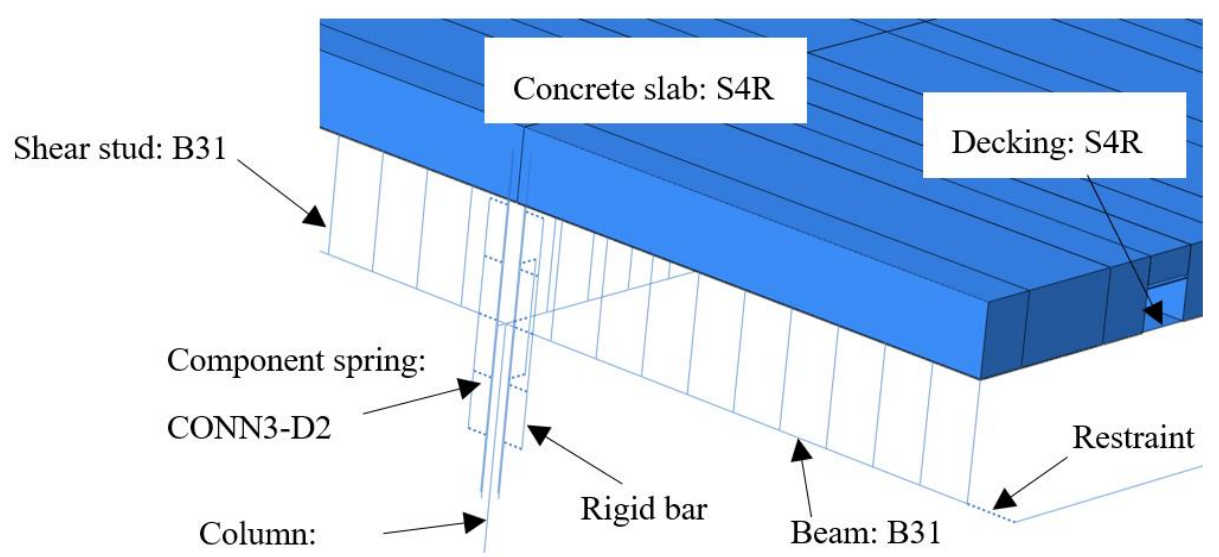

Fig. 3. Element used in models. 


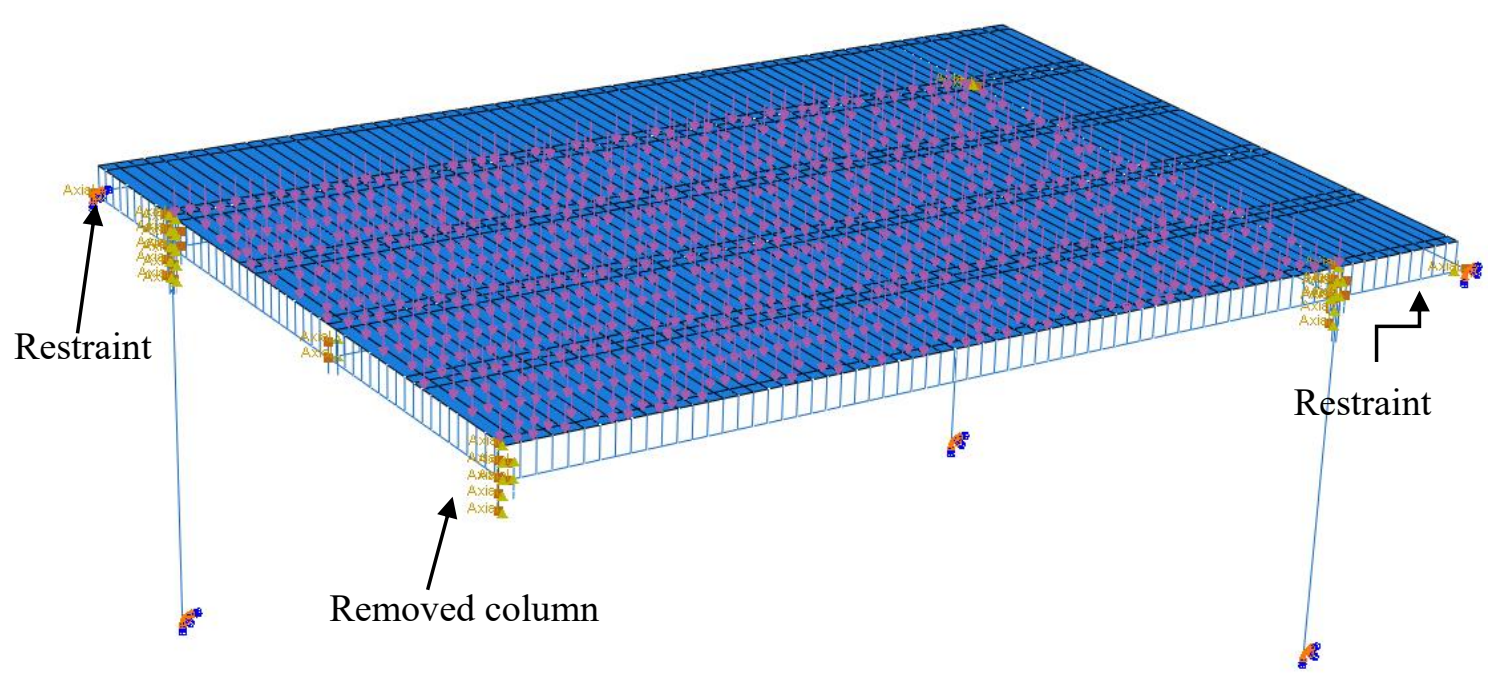

(a) Model under UDL

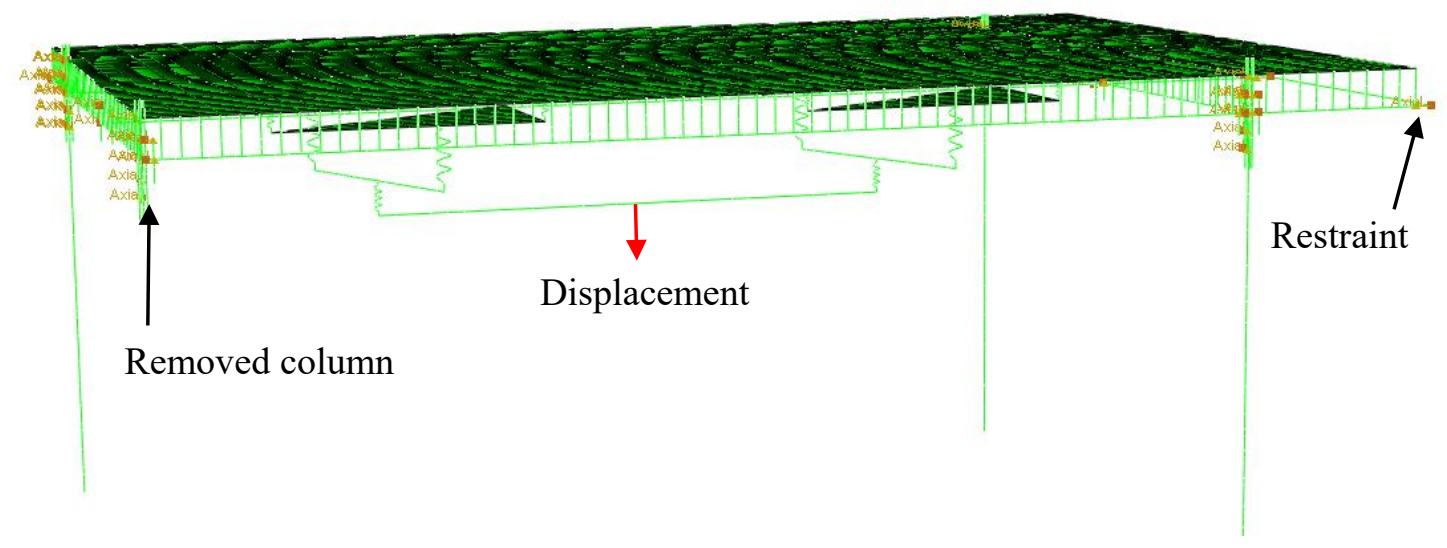

(b) Model under 12-point load

Fig. 4. Overviews of models.

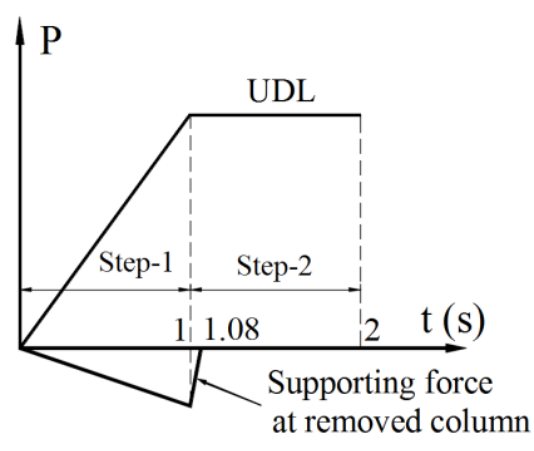

Fig. 5. Loading scheme.

\section{Simulation Results}

\subsection{Static behaviour}

\subsubsection{Static behaviour of floor systems under} CC scenario

Fig. 6 shows that the load-deflection responses of the model under UDL and 12point loads are the same in the ascending stage. The ultimate (maximum) load is 165 $\mathrm{kN}$, while the correpsonding deflection is 71 $\mathrm{mm}$. Afterwards, there is no increase in UDL but a signficant deflection of the slab, indicating failure of the composite floor system. Although the floor system starts failing, the UDL will not decrease since it is in 
force control. In contrast, the advantage of 12point loading is in displacment control, so that the descending branch can be captured. Considering the good agreement between load-defledction curves before the ultimate state, UDL can be substituted by 12-point loads. Besides, the failure modes of the floor system under the two loading methods are the same. As shown in Fig. 7, for both loading scenarios, the decrease in load is initiated by the failure of the slab at the hogging ends of girder B2 and beam B4 (Fig. 1) due to cantilever action. From Fig. 6, it can be seen that the composite floor system under $\mathrm{CC}$ removal scenario fails in a very brittle manner. The reason is that Catenary Action (CA) and Tensile Membrane Action (TMA) are not formed. The load is mainly resisted through cantilever action in girder B2, beam B4 and
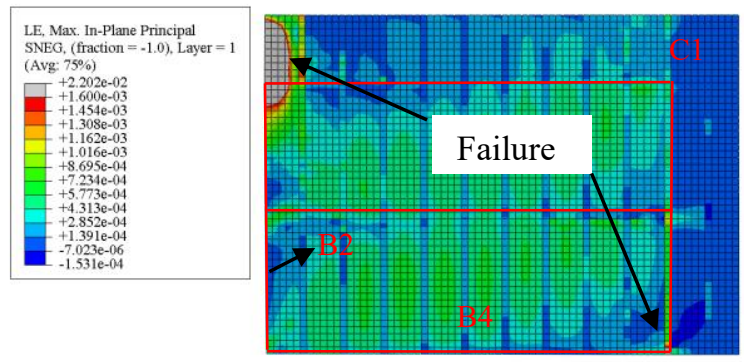

(a) Under UDL the slab, indicated by the failure modes of the slabs (Fig. 7 and Fig. 8). Since CA is not formed, all the joint components remain intact till the end. The failure mechanism under the $\mathrm{CC}$ removal scenario is totally different from that under an IC removal scenario, as simply compared in the following section.

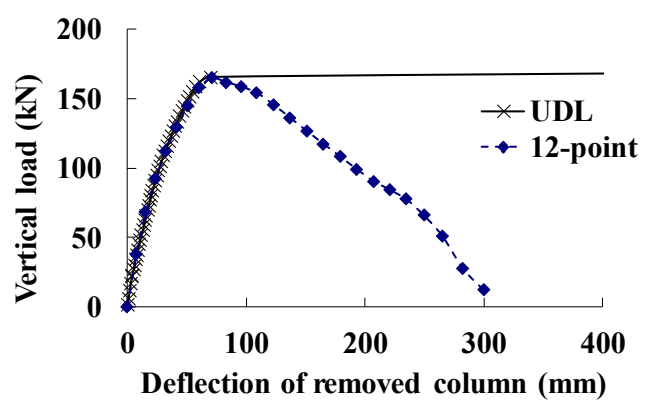

Fig. 6. Load-deflection curves of composite floor systems under CC removal scenario

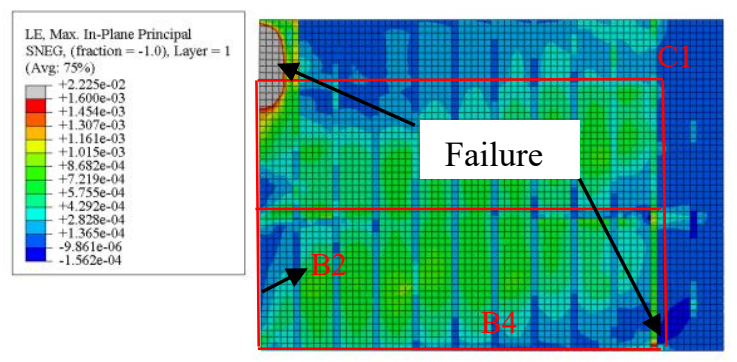

(b) Under 12-point loads

Fig. 7. In-plane principal strain distribution of steel decking at the ultimate state (peak load point).
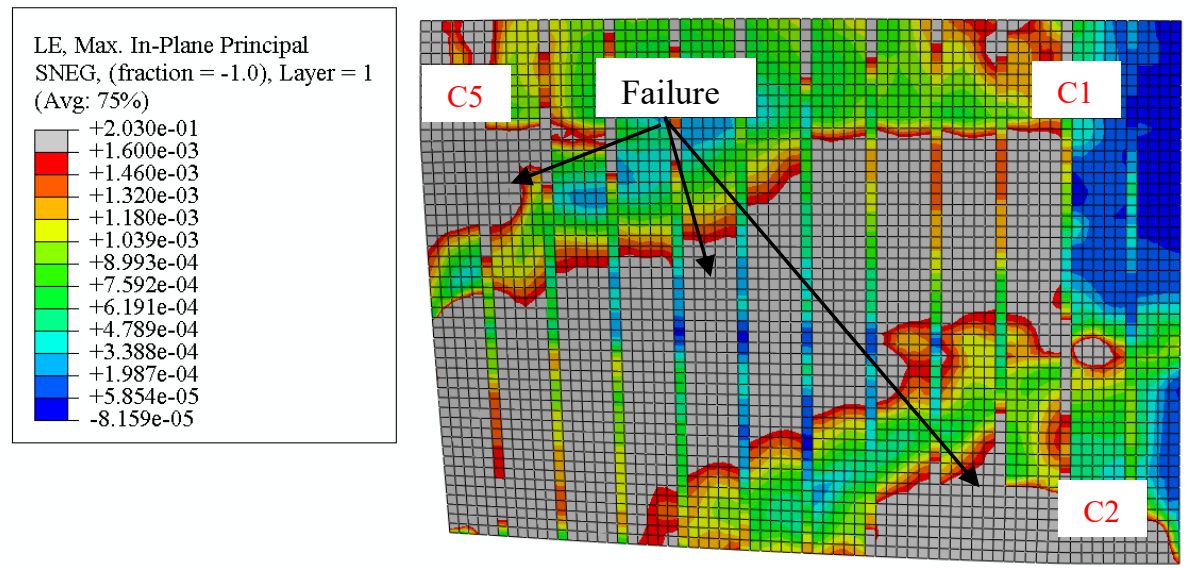

Fig. 8. In-plane principal strain distribution of steel decking when slab collapses.

\subsubsection{Comparison among different column removal scenarios}

For composite floor systems under an IC removal scenario, TMA can be mobilised [8]. Failure of the slab would not lead to the collapse of the entire floor system, since the failed slabs can be supported by CA in the doble-span girder and the double-span beam above the missing column. Alternatively, it is the complete failure of joint components at girder-to-removed column and beam-toremoved column connections governs the collapse of the floor system, when joint 
components at the hogging moment ends of the double-span girder and the double-span beam are also severely damaged [8]. In this way, composite floor systems under an IC removal scenario can sustain greater loads and have much better ductility compared with those under a CC removal scenario, as shown in Fig. 9. It is evidently observed that the performance of the composite floor system subjected to penultimate External (PE) column removal scenario is in bettwen those under $\mathrm{CC}$ and IC scenarios (Fig. 9). It should be noted that the modelling method under $\mathrm{CC}$, IC and PE scenarios is the same with only differences in column removal locations, as shown in Fig. 1 and Fig. 10.

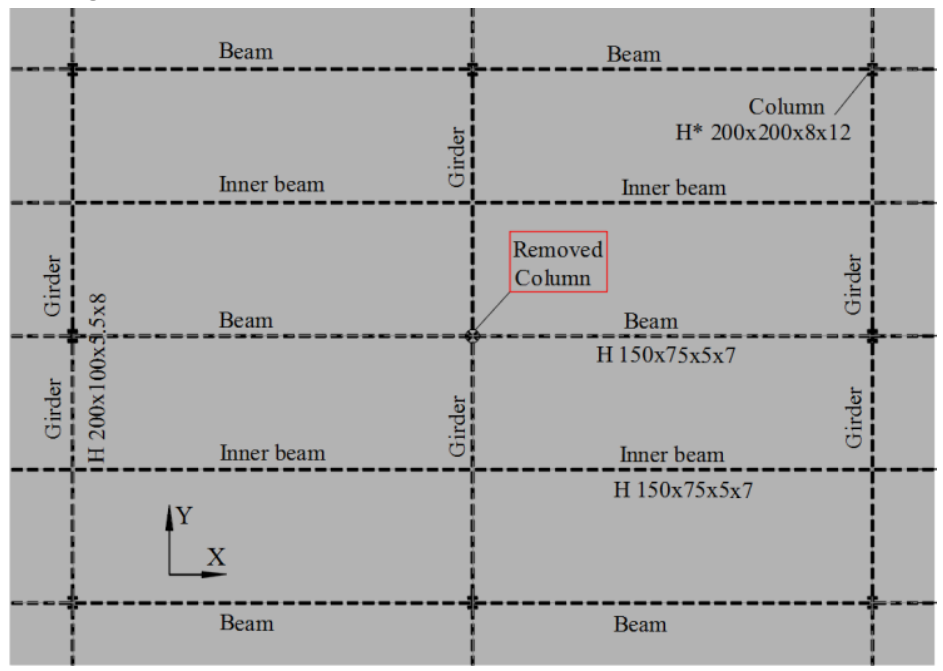

(a) IC removal scenario

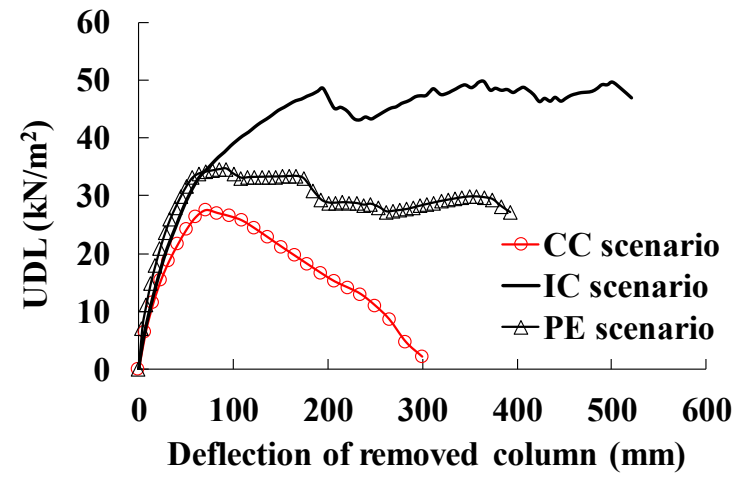

Fig. 9. Load-deflection curves under different column removal scenarios.

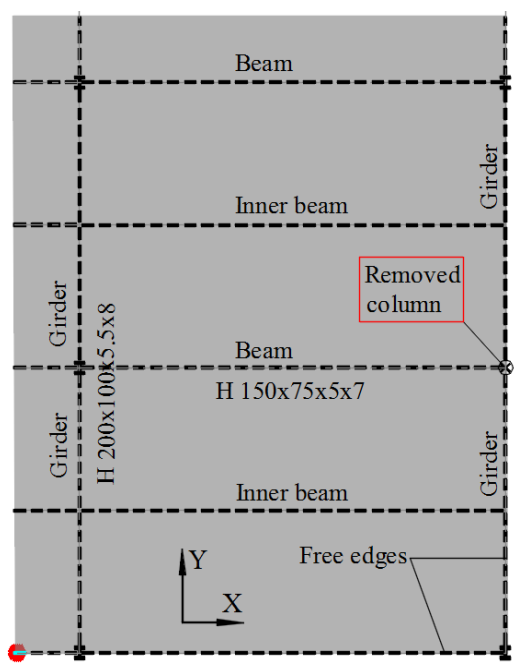

(b) PE column removal scenario

Fig. 10. Different column remvoal scenarios.

\subsection{Dynamic behaviour}

\subsubsection{Dynamic responses and failure mode}

Fig. 11 (a) shows the deflection-time responses at the removed column location under increasing levels of vertical loads. If an applied load is smaller than $150 \mathrm{kN}$, the deflection at the removed-column location reaches the first peak within $0.03 \mathrm{~s} \sim 0.06 \mathrm{~s}$ after the complete removal of the column at $1.08 \mathrm{~s}$. The floor system continues to vibrate for a few circels, then rests at an permernent deflection which is samller than the first peak value. As shown Fig. 11, when applying UDL with the total load value of $150 \mathrm{kN}$, the deflection continutes to increase until collapse occurs. If the floor system sustained a greater load (say $180 \mathrm{kN}$ ), sudden removal of the column leads to a significant drop of the floor with more than $500 \mathrm{~mm}$ of deflection at the removed column location, which can be regarded as an immediate collapse, as shown in Fig. 11 (b).

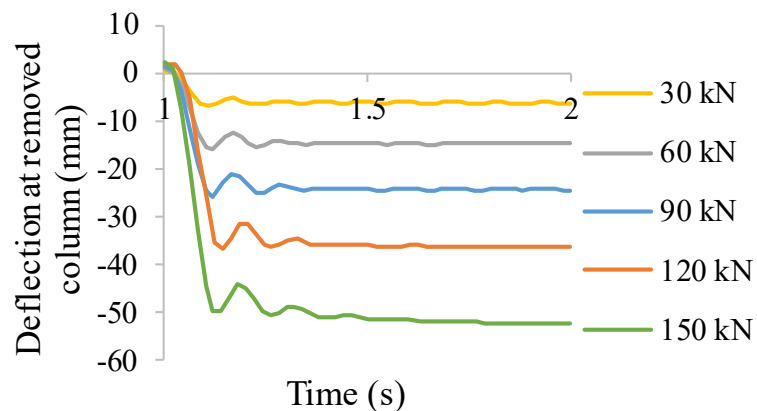

(a) Survival 


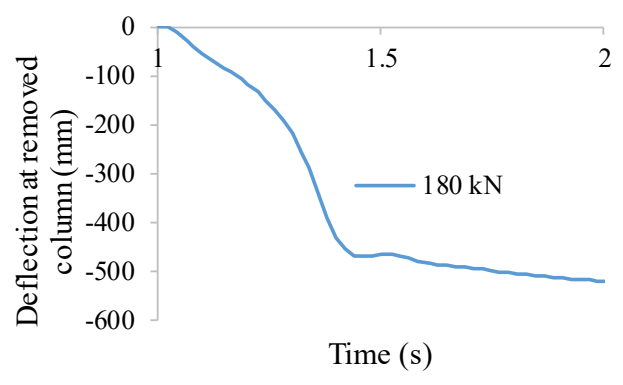

(b) Sudden collapse

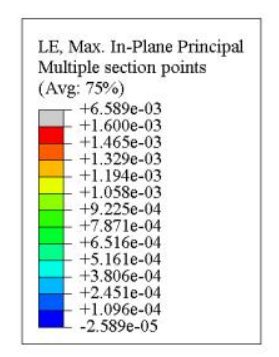

Fig. 11: Deflection-time responses under different levels of loads

Fig. 12 shows the failure mode of the slab subjected to sudden cornner column loss under a total load of $150 \mathrm{kN}$, which is similar to that under quasi-static senario (Fig. 7). Besides, all the joint components remain intact in both quasi-static and dynamic scenarios even for the case under a load of $180 \mathrm{kN}$.

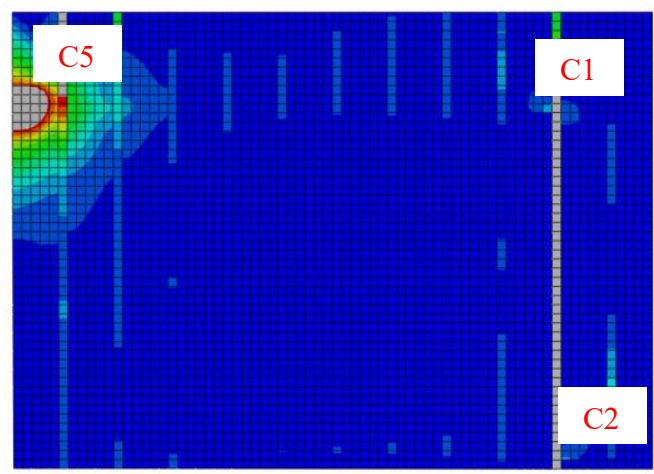

Fig. 12. In-plane principal strain distribution of steel decking under a load of $150 \mathrm{kN}$ at $1.14 \mathrm{~s}$ (first peak deflection).

\subsubsection{Dynamic increase factor (DIF)}

As shown in Fig. 11 (a), different levels of loads and the corresponding peak deflections constitude the pseudo-static response of the floor system subjected to a sudden corner-column-removal scenario (Fig. 13). DIF can be obtained through dividing the static load (Fig. 9) by the pseudo-static load based on the same deflection, as shown in Fig. 14 where the deflection is normalised as rotation $\left(\theta_{\mathrm{pra}} / \theta_{\mathrm{yb}}\right)$ of the primary member (girder). The terms $\theta_{\mathrm{pra}}$ and $\theta_{\mathrm{yb}}$ indicate plastic and yield rotations of the girders. It can be seen the DIF for the CC removal scenario decreases from around 1.1 to 1.0 with increasing deflection, which is much smaller than that under the IC removal scenario. However, this finding from the numerical results needs further verifications by actual tests.

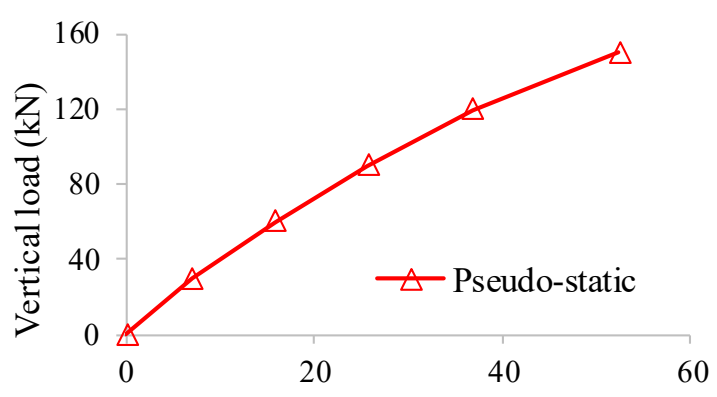

Deflection of the removed column (mm)
Fig. 13. Pseudo-static response.

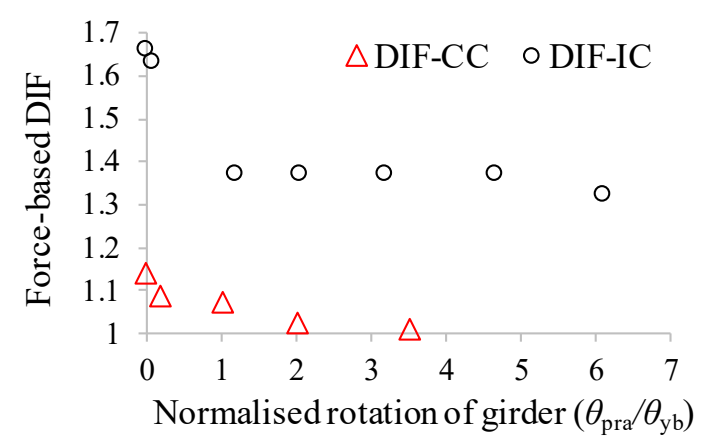

Fig. 14. DIF under IC and CC scenario.

\section{Conclusions}

Based on numerical simulations, this paper presents static and dynamic behaviour of 3D composite floor systems under a corner column removal scenario. It is found that the respective static load-carrying and deforamtion capacities of the composite floor system are $165 \mathrm{kN}$ and $71 \mathrm{~mm}$, while those under dynamic loading are $150 \mathrm{kN}$ and $52 \mathrm{~mm}$. Under a corner column removal scenario, the 
load is mainly resisted by cantilever action in the girder, beam and slab. The floor system is failed by the slab failure at the hogging moment ends of the cantilever girder, beam and slab. Consequently, composite floor systems under a corner column removal scenario fail in a rather brittle manner. However, Dynamic Increase Factor (DIF) for $\mathrm{CC}$ removal scenario is much smaller than that under IC scenario.

\section{References}

[1] Qian K, Li B. Slab effects on response of reinforced concrete substructures after loss of corner column. ACI Structural Journal 2012;109:845-55.

[2] Qian K, Li B. Quantification of Slab Influences on the Dynamic Performance of RC Frames against Progressive Collapse. Journal of Performance of Constructed Facilities 2015;29:04014029.

[3] LIM NS. Systematic Study on Reinforced Concrete Structures Under Progressive Collapse: Nanyang Technological University; 2017.

[4] Chen J, Huang X, Ma R, He M. Experimental Study on the Progressive Collapse Resistance of a Two-Story
Steel Moment Frame. Journal of Performance of Constructed Facilities 2012;26:567-75.

[5] Hull LA. Experimental Testing of a Steel Gravity Frame with a Composite Floor under Interior Column Loss: The University of Texas at Austin; 2013.

[6] Song BI, Sezen H. Experimental and analytical progressive collapse assessment of a steel frame building. Engineering Structures 2013;56:664-72.

[7] Johnson ES, Meissner JE, Fahnestock LA. Experimental Behavior of a Half-Scale Steel Concrete Composite Floor System Subjected To Column Removal Scenarios. Journal of Structural Engineering 2016;142:04015133.

[8] Fu QN, Tan KH, Zhou XH, Yang B. Load-resisting mechanisms of 3D composite floor systems under internal column-removal scenario. Engineering Structures 2017;148:357-72.

[9] Fu QN, Tan KH, Zhou XH, Yang B. Experimental study on 3d composite floor systems under columnremoval scenarios. J Struct Eng-ASCE 2018;in press.

[10] Fu QN, Tan KH, Yang B, J. L. Numerical Studies on Robustness of 3D Steel-Frame-Composite-Floor Systems Under Column Removal Scenario. 13th International Conference on Steel, Space and Composite Structures. Perth, Australia; 2018. 